\title{
CCEEN
}

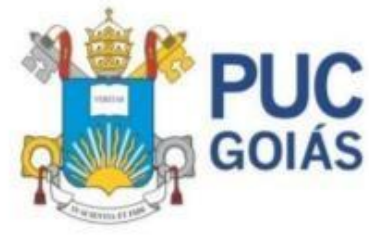

PONTIFÍCIA UNIVERSIDADE CATÓLICA DE GOIÁS

CEEN - ENFERMAGEM, NUTRIÇÃO, MEDICINA E MULTIPROFISSIONAIS PÓS-GRADUAÇÃO LATO SENSU EM UNIDADE DE TERAPIA INTENSIVA

https://doi.org/10.47820/recima21.v2i10.889

GIOVANNA RINCO DE OLIVEIRA

SÍNDROME DE BURNOUT EM ENFERMEIROS ATUANTES EM UNIDADE DE TERAPIA INTENSIVA

GOIÂNIA-GOIÁS

2021

GIOVANNA RINCO DE OLIVEIRA 


\section{SÍNDROME DE BURNOUT EM ENFERMEIROS ATUANTES EM UNIDADE DE TERAPIA INTENSIVA}

Trabalho apresentado ao Curso de Pós-Graduação Lato Sensu em Unidade de Terapia Intensiva, do Centro de Estudos de Enfermagem e Nutrição, em Chancela com a Pontifícia Universidade Católica de Goiás, para obtenção do título de Especialista, sob orientação da Dra Marislei Espíndula Brasileiro.

\section{GOIÂNIA-GOIÁS}

2021

FOLHA DE APROVAÇÃO

\section{GIOVANNA RINCO DE OLIVEIRA}

\section{SÍNDROME DE BURNOUT EM ENFERMEIROS ATUANTES EM UNIDADE DE TERAPIA INTENSIVA}

Trabalho apresentado ao Curso de Pós-Graduação Lato Sensu em Unidade de Terapia Intensiva, do Centro de Estudos de Enfermagem e Nutrição, em Chancela com a Pontifícia Universidade Católica de Goiás, para obtenção do título de Especialista, sob orientação da Dra Marislei Espíndula Brasileiro. 


\section{SUPLENTE}

\section{AGRADECIMENTOS}

Em primeiro lugar, a Deus, fonte de inspiração para seguir meu caminho, amigo fiel e companheiro, por me ter concedido paciência e oportunidade de percorrer nessa jornada e pela sabedoria com que guia os meus passos.

Aos colegas de sala e amigos, pelo companheirismo, amizade e pelos grandes desafios enfrentados juntos, pela coragem e imensa força de vontade de vencer, que fez com que prosseguíssemos em busca dessa tão grande realização de nossas vidas.

Ao meu orientador, pela dedicação, conhecimento, esforços, comprometimento e exemplo de profissionalismo repassado durante a realização deste Trabalho de Conclusão de Curso. 
A todas as pessoas, que direta ou indiretamente, fizeram parte desse estudo. Muito obrigado!

\section{Epígrafe}

"Devemos ser a Enfermagem que queremos ter"

Dra Marislei Espíndula Brasileiro 


\section{SUMÁRIO}

RESUMO

ABSTRACT

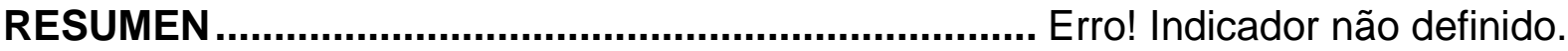

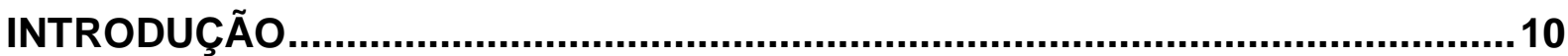

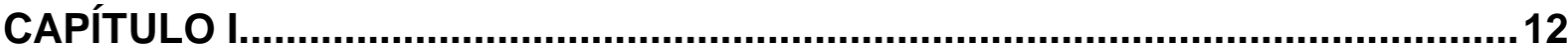

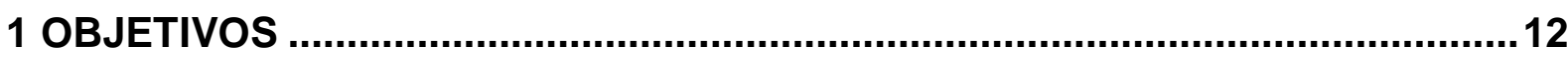

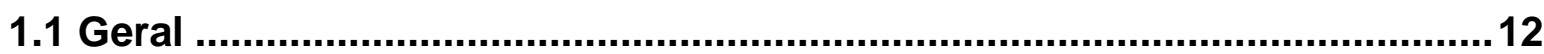

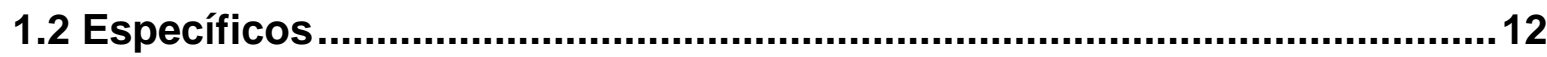

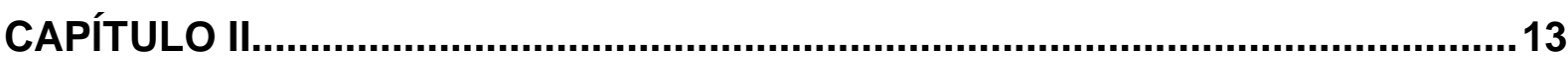

2 PROCEDIMENTOS METODOLÓGICOS...........................................................13

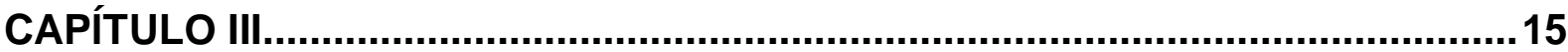

3 RESULTADOS E DISCUSSÃO

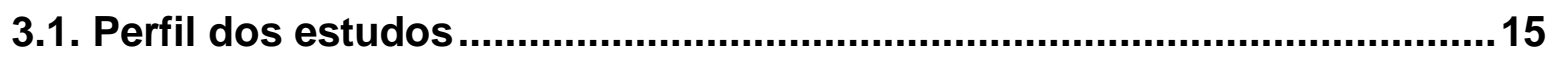

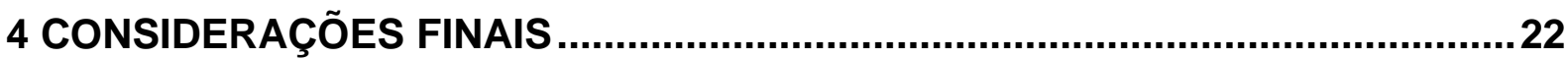

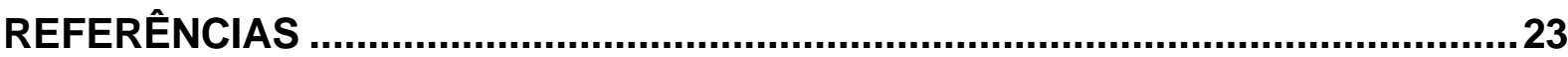




\section{RESUMO}

Objetivo: identificar as possíveis consequências da síndrome de burnout nos enfermeiros atuantes na unidade de terapia intensiva. Metodologia: Trata-se de uma revisão da literatura. Para levantamento dos artigos foi realizado busca online na Biblioteca Virtual de Saúde (BVS), usando os seguintes descritores de saúde (Decs): esgotamento profissional, enfermeiro e UTI. Resultados: $O$ ritmo apressado das transformações sociais, organizacionais e jurídicas tem influenciado no processo de saúde/ adoecimento do trabalhador. Entre as profissões que mais têm desenvolvido a síndrome do Burnout encontra-se a Enfermagem. Esse episódio relaciona-se ao intenso trabalho em turnos, à carência de reconhecimento profissional, às relações de trabalho e ao lidar constantemente com a sensação de impotência frente à morte. Para os profissionais que trabalham nas unidades de terapia intensiva (UTI) esta condição se agrava, pois estão mais expostos as condições dolorosas como a morte e o contato consecutivo com pacientes em estado grave ou terminal. Considerações finais: $O$ trabalho não deve ser um fardo pesado, mas uma atividade que proporcione satisfação e realização pessoal, portanto para se prevenir a Síndrome de Burnout devem-se adotar ações que valorize o profissional e the permita expressar a sua opinião sobre o ambiente de trabalho em que ele está inserido.

Descritores: Esgotamento profssional. Enfermeiro. UTI. 


\begin{abstract}
Objective: to identify the possible consequences of burnout syndrome in nurses working in the intensive care unit. Methodology: This is a literature review. To survey the articles, an online search was performed at the Virtual Health Library (VHL), using the following health descriptors (Decs): professional exhaustion, nurse and ICU. Results: The fast pace of social, organizational and legal transformations has influenced the worker health / illness process. Among the professions that have developed the burnout syndrome the most is nursing. This episode is related to intense shift work, lack of professional recognition, working relationships and constantly dealing with the feeling of helplessness in the face of death. For professionals working in intensive care units (ICU) this condition worsens because painful conditions such as death and consecutive contact with patients in severe or terminal condition are more exposed. Final considerations: Work should not be a heavy burden, but an activity that provides satisfaction and personal fulfillment. Therefore, to prevent Burnout Syndrome, actions should be taken that value the professional and allow him to express his opinion about the work environment. job in which it is inserted.
\end{abstract}

Descriptors: Professional exhaustion. Nurse. ICU. 


\section{INTRODUÇÃO}

Segundo a OMS (2019), a Síndrome de Burnout ou Síndrome de esgotamento profissional, é marcada como uma síndrome ocupacional, configurada por três sinais clássicos: esgotamento físico e psíquico (a sensação de não dar conta das tarefas); indiferença e perda de personalidade (não se importar mais com o próprio exercício profissional, cinismo e apatia); e Baixo contentamento profissional.

A síndrome de burnout ultrapassa o estresse, sendo avaliada como uma reação ao estresse crônico. A síndrome está relacionada ao trabalho causada por repetitivas pressões emocionais sofridas pelos profissionais ao longo do tempo.

A síndrome de burnout constitui em um processo social-psicológico e multidimensional, indicado pela presença de 3 extensões independentes: a) a exaustão emocional, marcada por redução da capacidade física e esgotamento emocional; b) a despersonalização, que se menciona a respostas frias e atitudes impessoais com os usuários do serviço; e c) a baixa concretização profissional, que representa uma tendência à negatividade em seu desempenho e desenvolvimento profissional (FERREIRA, 2017).

O risco maior de enfrentar o Burnout ocorre em profissionais da educação, da saúde, policiais e agentes penitenciários, entre outros, por se tratar de ofícios que requerem muito envolvimento com os problemas e pensamentos diversos. $O$ estresse ocupacional pode provocar impacto para o próprio trabalho do indivíduo e nas diferentes áreas da sua vida, na expansão em que há uma inter-relação entre todas elas (SILVA, 2016).

As consequências da síndrome são rigorosas e em muitos casos irreversíveis. Em alto nível o Burnout faz com que os profissionais esperem um curto tempo de trabalho, longo período de férias ou até mesmo a demissão. Entre os motivos ligados ao desenvolvimento da síndrome de Burnout estão: desejo de reconhecimento, subvalorização profissional, necessidade de superação profissional, sobrecarga de trabalho; trabalho em conjunto, autonomia e particularidades da tarefa ou rotina de trabalho (SILVA, 2014).

Teoricamente, o Burnout depende da suscetibilidade individual e do ambiente em que o profissional está introduzido, incluindo desde o local de trabalho diário até a sociedade a qual o indivíduo pertence. Intervenções capazes de aperfeiçoar os recursos pessoais para lidar com os desafios do ambiente podem auxiliar no controle 
dessa síndrome. Pesquisas comprovam que os aspectos negativos do ambiente de trabalho apresentam relação com eventos adversos associados ao cuidado de baixa qualidade e aumentam o risco de consequências indesejáveis para os profissionais de saúde, como a ocorrência de Burnout (NOGUEIRA, 2018).

A enfermagem mostra-se como uma das profissões com amplas possibilidades de desencadear a síndrome de burnout, tendo em vista a organização do trabalho, a indefinição do papel profissional; a sobrecarga de trabalho acirrada pelo pagamento de horas-extras; a falta de autonomia e autoridade na tomada de decisões, além de ter o cuidado como sua essência e por grande parte da carga de trabalho ser o contato direto com pacientes e familiares (ROSSI, 2010).

Enfermeiros de unidade de terapia intensiva suportam influência contínua de diversos estressores encontrados no ambiente laboral. Devido ao trabalho exaustivo e tenso, esses profissionais estão mais predispostos a desenvolver o estresse ocupacional, que com o tempo pode desenvolver a síndrome de burnout, assim como outros transtornos mentais.

O burnout e o estresse são os assuntos mais abordados por pesquisadores da área de saúde mental no trabalhador. Tem sido relatado que o burnout entre os enfermeiros é mais elevado do que em outros profissionais da saúde, uma vez que eles experimentam situações estressantes constantes no trabalho, além de atuarem em contato direto com os pacientes críticos que têm diagnósticos diferentes e graus de sofrimento diversos (VASCONCELOS, 2018).

Sendo assim para concretizar esta pesquisa partimos do seguinte problema: Como a síndrome de burnout afeta o trabalho dos enfermeiros na unidade de terapia intensiva?

Essa pesquisa se justifica pela necessidade de maior investigação e divulgação acerca da síndrome de burnout na área hospitalar, visto que, por lidar diretamente com seres humanos, os profissionais dessa área estão mais expostos aos fatores desencadeantes de estresse. Com isso, apresentam maior probabilidade de desenvolver a síndrome de burnout. Além disso, compreender a síndrome na dimensão organizacional possibilita detectar precocemente suas causas, prevenindo a sintomatologia e impactando positivamente a produtividade, o desempenho e a eficácia do serviço prestado por esse profissional. 


\section{CAPÍTULO I}

\section{OBJETIVOS}

1.1 Geral

Identificar as possíveis consequências da síndrome de burnout nos enfermeiros atuantes na unidade de terapia intensiva.

\subsection{Específicos}

Descrever sobre a síndrome de burnout nos enfermeiros

Citar os sinais e sintomas;

Verificar os tipos de tratamentos;

Detectar as complicações atuantes na assistência de enfermagem. 


\section{CAPÍTULO II}

\section{PROCEDIMENTOS METODOLÓGICOS}

O presente artigo científico segue os moldes de uma pesquisa bibliográfica, com análise integrativa, visando fazer uma ilustração geral sobre complicações cirúrgicas pós - transplante renal.

A pesquisa classifica-se como bibliográfica, pois a revisão bibliográfica é o processo de levantamento e análise do que já foi publicado sobre o tema de pesquisa escolhido, permitindo efetuar um mapeamento do que já foi escrito e de quem já escreveu algo sobre o tema da pesquisa (MORESEI, 2003).

Após a definição do tema foi feita uma busca em bases de dados virtuais em saúde, especificamente na Biblioteca Virtual de Saúde - Bireme. Foram utilizados os descritores: Esgotamento profssional, enfermeiro, UTI, enfermagem. O passo seguinte foi uma leitura exploratória das publicações apresentadas no Sistema LatinoAmericano e do Caribe de informação em Ciências da Saúde - LILACS, National Library of Medicine - MEDLINE e Bancos de Dados em Enfermagem - BDENF, Scientific Electronic Library online - Scielo. Os critérios de inclusão foram: serem publicados nos últimos dez anos e responderem aos objetivos do estudo. Foram excluídos os anteriores que não respondiam aos objetivos.

Para o resgate histórico utilizou-se livros e revistas impressas que abordassem o tema e possibilitassem um breve relato da evolução do transplante renal.

Realizada a leitura exploratória e seleção do material, principiou a leitura analítica, por meio da leitura das obras selecionadas, que possibilitou a organização das ideias por ordem de importância e a sintetização destas que visou a fixação das ideias essenciais para a solução do problema da pesquisa.

Após a leitura analítica, iniciou-se a leitura interpretativa que tratou do comentário feito pela ligação dos dados obtidos nas fontes ao problema da pesquisa e conhecimentos prévios. Na leitura interpretativa houve uma busca mais ampla de resultados, pois ajustaram o problema da pesquisa a possíveis soluções. Feita a leitura interpretativa se iniciou a tomada de apontamentos que se referiram a anotações que consideravam o problema da pesquisa, ressalvando as ideias principais e dados mais importantes. 
A partir das anotações da tomada de apontamentos, foram confeccionados fichamentos, em fichas estruturadas em um documento do Microsoft word, que objetivaram a identificação das obras consultadas, o registro do conteúdo das obras, o registro dos comentários acerca das obras e ordenação dos registros. Os fichamentos propiciaram a construção lógica do trabalho, que consistiram na coordenação das ideias que acataram os objetivos da pesquisa.

As ideias mais importantes dos estudos foram inseridas em um quadro sinóptico, que consistiu na desconstrução dos estudos, dividido em quatro colunas: 1) numeração dos estudos, 2) resultados das pesquisas e suas referências. A leitura repetida dos resultados, em busca dos pontos comuns entre eles resultou em uma terceira coluna: 3) pontos comuns entre os resultados das pesquisas, onde se descreveu em que os autores concordaram. O último passo foi a construção das categorias, que consistiu na síntese de cada ponto comum. 


\section{CAPÍTULO III}

\section{RESULTADOS E DISCUSSÃO}

\subsection{Perfil dos estudos}

\begin{tabular}{|c|c|c|c|}
\hline Autor (Ano) & Título & Principais Resultados & Conclusão \\
\hline BEZERRA, 2009. & $\begin{array}{lc}\text { A síndrome } & \text { de } \\
\text { burnout } & \text { em } \\
\text { enfermeiros } & \text { da } \\
\text { equipe } & \text { de } \\
\text { resgate pré- } \\
\text { hospitalar. }\end{array}$ & $\begin{array}{l}\text { No grupo estudado de } 17 \\
\text { enfermeiros, } 76 \% \text { eram do sexo } \\
\text { feminino. A idade teve uma } \\
\text { variação de } 30 \text { a } 49 \text { anos (média } \\
\text { de } 37 \text { anos, desvio padrão de } \\
\text { quatro anos e mediana de } 38 \text { ). } \\
\text { Quanto ao estado civil, houve } \\
\text { igual frequência de profissionais } \\
\text { casados e solteiros ( } 35 \% \text { cada). } \\
\text { E } 53 \% \text { da amostra estudada } \\
\text { referiram não terem filhos. A } \\
\text { maioria dos enfermeiros, } 59 \% \\
\text { referiu ter de cinco a dez anos de } \\
\text { atuação na profissão. Com } \\
\text { relação à naturalidade, } 47 \% \text { dos } \\
\text { enfermeiros nasceram em São } \\
\text { Paulo (Capital). Toda a amostra } \\
\text { deste estudo é composta por } \\
\text { brasileiros. }\end{array}$ & $\begin{array}{l}\text { No presente estudo } \\
\text { demonstrou-se que nesta } \\
\text { amostra, apesar de se } \\
\text { tratar de uma população } \\
\text { considerada de riscos } \\
\text { ocupacionais, não houve } \\
\text { presença da síndrome de } \\
\text { burnout. }\end{array}$ \\
\hline $\begin{array}{l}\text { FERREIRA, } \\
2017 .\end{array}$ & $\begin{array}{lr}\text { Síndrome } & \text { de } \\
\text { burnout } & \text { na } \\
\text { enfermagem } & \\
\text { hospitalar } & \text { / } \\
\text { intensivista: } & \text { o } \\
\text { que dizem } & \text { os } \\
\text { estudos? } & \end{array}$ & $\begin{array}{ll}\text { Três categorias } & \text { temáticas } \\
\text { surgiram com base na leitura das } \\
\text { publicações - } \\
\text { sofrimento do } & \text { profissional; } \\
\text { características } & \text { individuais; } \\
\text { suporte institucional. }\end{array}$ & $\begin{array}{l}\text { O interesse } r \text { da } \\
\text { comunidade científica } \\
\text { pelos estudos sobre a SB } \\
\text { e seus resultados tem } \\
\text { aumentado nos últimos } \\
\text { anos, principalmente } \\
\text { entre profissionais da } \\
\text { saúde, devido às graves } \\
\text { consequências r que } \\
\text { podem produzir na } \\
\text { qualidade dos cuidados } \\
\text { aos pacientes, sendo } \\
\text { essa uma problemática } \\
\text { comum em diversos } \\
\text { países. Contudo, o Brasil } \\
\text { ainda precisa avançar } \\
\text { nos estudos sobre essa } \\
\text { doença ocupacional, pois } \\
\text { se observa } \\
\text { vulnerabilidade entre os } \\
\text { profissionais da saúde } \\
\text { quanto à } \\
\text { potencializada sB, } \\
\text { identificação da elevada } \\
\text { presença de cada uma de } \\
\text { suas dimensões no } \\
\text { contexto hospitalar - }\end{array}$ \\
\hline
\end{tabular}




\begin{tabular}{|c|c|c|c|}
\hline & & & $\begin{array}{l}\text { principalmente em áreas } \\
\text { complexas, como a UTI. }\end{array}$ \\
\hline $\begin{array}{l}\text { FONSECA, } \\
2016 .\end{array}$ & $\begin{array}{l}\text { Síndrome de } \\
\text { burnout entre } \\
\text { profissionais de } \\
\text { enfermagem de } \\
\text { unidades } \\
\text { intensivas em } \\
\text { um hospital } \\
\text { público. }\end{array}$ & $\begin{array}{l}\text { Do total de } 22 \text { entrevistados, } 9 \\
\text { (40,9\%) profissionais } \\
\text { apresentam um nível alto de } \\
\text { exaustão emocional, estão } \\
\text { sofrendo com ou no seu trabalho, } \\
\text { apresentam sensação de } \\
\text { esgotamento físico e mental, e } \\
\text { não possuem disposição de } \\
\text { energia para realização de } \\
\text { qualquer atividade. Seis }(27,3 \%) \\
\text { profissionais vivenciam tais } \\
\text { sintomas poucas vezes, no } \\
\text { entanto sete (31,8\%) } \\
\text { apresentam um nível médio de } \\
\text { exaustão emocional, } \\
\text { experimentam seus sintomas } \\
\text { algumas vezes, o que deve ser } \\
\text { considerado um sinal de alerta. }\end{array}$ & $\begin{array}{l}\text { Com este estudo, foi } \\
\text { possível identificar que a } \\
\text { sobrecarga relativa ao } \\
\text { trabalho representa um } \\
\text { risco à saúde dos } \\
\text { profissionais que atuam } \\
\text { em unidades intensivas } \\
\text { devido às situações de } \\
\text { desgaste que enfrentam } \\
\text { no seu dia-a-dia. }\end{array}$ \\
\hline GALINDO, 2012. & $\begin{array}{l}\text { Síndrome de } \\
\text { burnout entre } \\
\text { enfermeiros de } \\
\text { um hospital } \\
\text { geral da cidade } \\
\text { de recife. }\end{array}$ & 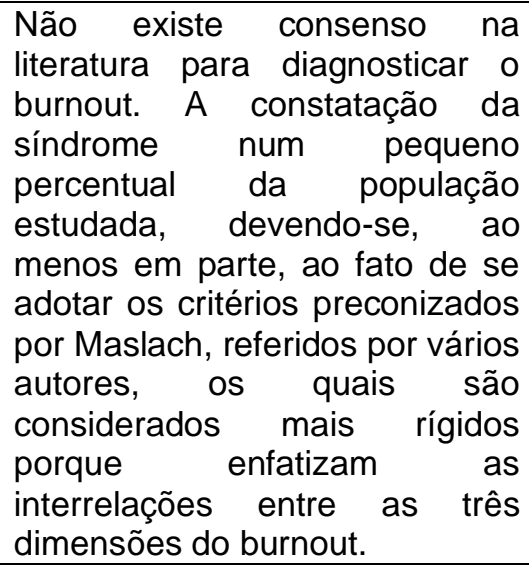 & $\begin{array}{l}\text { A frequência de burnout } \\
\text { era baixa na população } \\
\text { estudada, mas os } \\
\text { resultados despertam } \\
\text { preocupação, } \\
\text { particularmente, devido } \\
\text { ao caráter sorrateiro da } \\
\text { síndrome, uma vez que } \\
\text { algum dos seus } \\
\text { sentimentos e atitudes } \\
\text { constituintes pode estar } \\
\text { presente de modo } \\
\text { intermitente, avançando } \\
\text { com o tempo. }\end{array}$ \\
\hline MORENO, 2011. & $\begin{array}{l}\text { Estratégias e } \\
\text { intervenções no } \\
\text { enfrentamento } \\
\text { da Síndrome de } \\
\text { burnout. }\end{array}$ & $\begin{array}{l}\text { Foram selecionados } 46 \text { artigos, } \\
\text { três dissertações e três livros. Os } \\
\text { estudos enfatizam três níveis de } \\
\text { intervenções, ou } \\
\text { seja, estratégias organizacionais } \\
\text { aplicadas ao ambiente de } \\
\text { trabalho; estratégias individuais } \\
\text { focadas nas respostas pessoais, } \\
\text { ao tentar regular } \\
\text { as emoções frente a uma } \\
\text { situação umatressante } \\
\text { e estratégias combinadas } \\
\text { centradas na interação do } \\
\text { contexto ocupacional com o } \\
\text { indivíduo. }\end{array}$ & $\begin{array}{lr}\text { As ações } & \text { preventivas } \\
\text { serão viáveis } & \text { quando } \\
\text { a síndrome } & \text { de } \\
\text { burnout não } & \text { for } \\
\text { estigmatizada } & \\
\text { unicamente } & \text { como } \\
\text { responsabilidade } \\
\text { individual } \\
\text { ou pelo relacionamento } \\
\text { profissional-usuário, e ser } \\
\text { entendida como um } \\
\text { problema da relação } \\
\text { indivíduo - processo } \\
\text { de trabalho - organização }\end{array}$ \\
\hline $\begin{array}{l}\text { NOGUEIRA, } \\
2018 .\end{array}$ & $\begin{array}{lr}\text { Burnout } & \mathrm{e} \\
\text { ambiente } & \text { de } \\
\text { trabalho } & \text { de } \\
\text { enfermeiros } & \text { em } \\
\text { instituições } & \\
\text { públicas } & \text { de } \\
\text { saúde. } & \end{array}$ & $\begin{array}{l}\text { A realização de uma atividade } \\
\text { profissional deveria ser uma } \\
\text { fonte de satisfação, recompensa } \\
\text { econômica e profissional, que } \\
\text { reafirmasse o papel importante } \\
\text { do indivíduo na sociedade. No } \\
\text { entanto, a prática cotidiana é } \\
\text { vivenciada com a presença de } \\
\text { diferentes níveis de estresse } \\
\text { ocupacional que pode ter como }\end{array}$ & $\begin{array}{l}\text { As características do } \\
\text { ambiente de trabalho que } \\
\text { apresentaram relação } \\
\text { com Burnout dos } \\
\text { enfermeiros foram: a } \\
\text { autonomia, o suporte } \\
\text { organizacional e o } \\
\text { controle sobre } \quad \text { o } \\
\text { ambiente. A pouca } \\
\text { autonomia para o } \\
\text { enfermeiro }\end{array}$ \\
\hline
\end{tabular}




\begin{tabular}{|c|c|c|c|}
\hline & & $\begin{array}{l}\text { produto a condição patológica do } \\
\text { Burnout. }\end{array}$ & 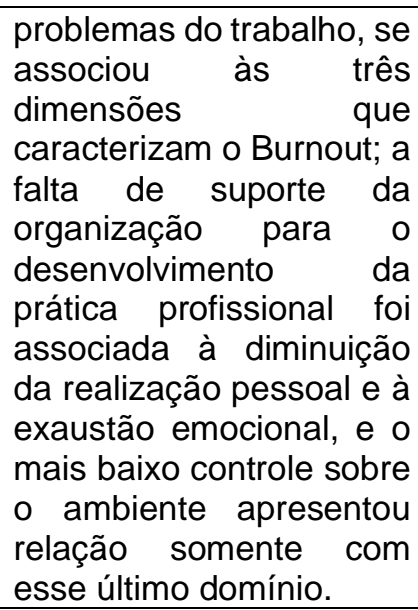 \\
\hline OLIVEIRA, 2013. & $\begin{array}{l}\text { Síndrome de } \\
\text { burnout em } \\
\text { enfermeiros: } \\
\text { uma revisão } \\
\text { integrativa. }\end{array}$ & $\begin{array}{l}\text { A importância de avaliar burnout } \\
\text { em profissionais de enfermagem } \\
\text { é, sobretudo, o fato de que } \\
\text { encontramos pessoas com alta } \\
\text { realização profissional, porém } \\
\text { vivem em um sistema fechado, } \\
\text { onde a comunicação é limitada, } \\
\text { onde aparecem como } \\
\text { consequência da profissão, o } \\
\text { esquecimento ou o deixar de } \\
\text { lado suas próprias atividades. }\end{array}$ & $\begin{array}{l}\text { A síndrome de burnout } \\
\text { destaca-se dentre as } \\
\text { doenças ocupacionais } \\
\text { desenvolvidas atividade } \\
\text { qualquer a ation } \\
\text { profissional, no entanto, a } \\
\text { enfermagem está entre } \\
\text { as profissões mais } \\
\text { acometidas, pelo fato das } \\
\text { próprias } \\
\text { atividades/situações } \\
\text { características inerentes } \\
\text { à profissão. }\end{array}$ \\
\hline ROSSI, 2010. & $\begin{array}{l}\text { A síndrome de } \\
\text { burnout no } \\
\text { enfermeiro: um } \\
\text { estudo } \\
\text { comparativo } \\
\text { entre a atenção } \\
\text { básica e setores } \\
\text { fechados } \\
\text { hospitalares. }\end{array}$ & $\begin{array}{l}\text { Em relação à sintomatologia } \\
\text { pode-se encontrar diversos } \\
\text { fatores associados ao burnout, } \\
\text { destacando-se a fadiga, dores } \\
\text { musculares, distúrbios do sono, } \\
\text { cefaleias, perturbações } \\
\text { gastrointestinais e hipertensão } \\
\text { arterial. }\end{array}$ & $\begin{array}{l}\text { No campo da saúde do } \\
\text { trabalhador, entendemos } \\
\text { como relevante a } \\
\text { construção do } \\
\text { conhecimento de } \\
\text { possíveis predisposições } \\
\text { desencadeantes da } \\
\text { síndrome do } \\
\text { esgotamento profissional, } \\
\text { em especial nos } \\
\text { enfermeiros, visto que } \\
\text { atuam em diferentes } \\
\text { ambientes de trabalho, } \\
\text { muitas das vezes em } \\
\text { condições inadequadas, } \\
\text { tanto nos aspectos físico, } \\
\text { biológico e psicossocial. } \\
\text { Situações que podem } \\
\text { levar à alta frequência de } \\
\text { faltas ao trabalho, } \\
\text { pedidos de licença, } \\
\text { abandono do emprego e } \\
\text { deterioração da qualidade } \\
\text { dos serviços, gerando } \\
\text { impacto negativo sobre a } \\
\text { efetividade da atenção } \\
\text { oferecida aos pacientes. }\end{array}$ \\
\hline SILVA, 2014. & $\begin{array}{lr}\text { Síndrome } & \text { de } \\
\text { burnout } & \text { em } \\
\text { enfermeiros } & \\
\text { atuantes } & \text { em } \\
\text { unidade } & \text { de }\end{array}$ & $\begin{array}{l}\text { Ao correlacionar os dados } \\
\text { sociodemográficos } \\
\text { enfermeiros à presença da da } \\
\text { síndrome de Burnout, observou- } \\
\text { se que ambas eram do sexo }\end{array}$ & $\begin{array}{l}\text { A partir da investigação } \\
\text { realizada pode-se } \\
\text { concluir que a síndrome } \\
\text { de Burnout acontece de } \\
\text { forma discreta em }\end{array}$ \\
\hline
\end{tabular}




\begin{tabular}{|c|c|c|c|}
\hline & $\begin{array}{l}\text { terapia } \\
\text { intensiva. }\end{array}$ & $\begin{array}{l}\text { feminino, com faixa etária entre } \\
22 \text { a } 40 \text { anos, sem filhos, sendo } \\
\text { uma casada e a outra solteira. } \\
\text { Quanto à atividade física ambas } \\
\text { praticavam exercícios. Dessa } \\
\text { forma, os resultados exibidos } \\
\text { apresentam-se condizentes com } \\
\text { a literatura. }\end{array}$ & $\begin{array}{l}\text { enfermeiros de Unidades } \\
\text { de Terapia Intensiva nos } \\
\text { quatro hospitais de } \\
\text { ensino no município de } \\
\text { Teresina, Piauí. } \\
\text { Entretanto ressalta-se a } \\
\text { presença de sintomas } \\
\text { somáticos em grande } \\
\text { parte dos profissionais; o } \\
\text { que se traduz em } \\
\text { afecções físicas e } \\
\text { psicológicas importantes. }\end{array}$ \\
\hline SILVA, 2016. & $\begin{array}{lr}\text { Síndrome } & \text { de } \\
\text { burnout } & \text { em } \\
\text { profissionais } & \text { de } \\
\text { enfermagem } & \text { na } \\
\text { unidade } & \text { de } \\
\text { terapia } & \\
\text { intensiva. } & \end{array}$ & $\begin{array}{l}\text { A prevenção da Síndrome de } \\
\text { Burnout inicia com uma } \\
\text { mudança na rotina do local de } \\
\text { trabalho, procurando não atingir } \\
\text { metas, mas, incluindo o bem- } \\
\text { estar de cada um, vendo o } \\
\text { profissional dentro de uma } \\
\text { perspectiva holística e vendo o } \\
\text { ambiente de trabalho como um } \\
\text { todo, seja na climatização, na } \\
\text { diminuição dos ruídos, nos } \\
\text { recursos materiais para que } \\
\text { juntos, com uma valorização do } \\
\text { profissional, contribuam para seu } \\
\text { crescimento profissional. }\end{array}$ & $\begin{array}{l}\text { Os resultados obtidos } \\
\text { refletem que os } \\
\text { profissionais de saúde } \\
\text { apresentam } \\
\text { sugestivos da sinais } \\
\text { de Burnout, indicam } \\
\text { também que os } \\
\text { profissionais apresentam } \\
\text { um alto nível de } \\
\text { esgotamento emocional e } \\
\text { despersonalização, o que } \\
\text { acarreta problemas para } \\
\text { a saúde desses } \\
\text { indivíduos a onto } \\
\text { consequentemente, para } \\
\text { quem está próximo do } \\
\text { mesmo. O fator } \\
\text { organizacional social e } \\
\text { econômico englobam a } \\
\text { tríade que contribuem } \\
\text { para o agravamento } \\
\text { dessa síndrome. }\end{array}$ \\
\hline TAVARES, 2014. & $\begin{array}{lr}\text { Ocorrência } & \text { da } \\
\text { síndrome } & \text { de } \\
\text { Burnout } & \text { em } \\
\text { enfermeiros } & \\
\text { residentes. }\end{array}$ & $\begin{array}{l}\text { Diante dos resultados descritos, } \\
\text { nota-se que há similaridade com } \\
\text { aqueles encontrados na } \\
\text { literatura, o que evidencia que os } \\
\text { indivíduos com alterações } \\
\text { sugestivas para o o } \\
\text { desenvolvimento do Burnout } \\
\text { possuem características } \\
\text { semelhantes de suscetibilidade. } \\
\text { Em estudos realizados com } \\
\text { residentes de enfermagem e } \\
\text { profissionais de fisioterapia, } \\
\text { foram encontrados indivíduos } \\
\text { jovens, do gênero feminino, } \\
\text { solteiros, sem filhos e no início } \\
\text { de sua carreira profissional. }\end{array}$ & $\begin{array}{l}\text { Os resultados apontaram } \\
\text { para o desenvolvimento } \\
\text { da síndrome de Burnout } \\
\text { em um grupo de } \\
\text { residentes } \\
\text { enfermagem e revelaram } \\
\text { alguns indivíduos } \\
\text { propensos a ela. Ser } \\
\text { jovem, do gênero } \\
\text { feminino, solteiro, sem } \\
\text { filhos, e estar em início da } \\
\text { carreira profissional e } \\
\text { alocado em programas de } \\
\text { residência de alta } \\
\text { complexidade } \\
\text { (cardiovascular e terapia } \\
\text { intensiva) foram fatores } \\
\text { predisponentes à } \\
\text { síndrome de Burnout em } \\
\text { um grupo de residentes } \\
\text { de enfermagem. }\end{array}$ \\
\hline $\begin{array}{l}\text { VALERETTO, } \\
2013 .\end{array}$ & $\begin{array}{l}\text { Fatores } \\
\text { desencadeante } \\
\text { s do estresse } \\
\text { ocupacional e } \\
\text { da síndrome de }\end{array}$ & $\begin{array}{l}\text { Diante desta problemática, } \\
\text { torna-se necessário que as } \\
\text { instituições tenham um } \\
\text { planejamento, a fim de combater } \\
\text { o burnout. fazendo com que os }\end{array}$ & $\begin{array}{l}\text { Os resultados revelam } \\
\text { que a enfermagem se } \\
\text { encontra como profissão } \\
\text { de risco para o estresse } \\
\text { ocupacional e burnout }\end{array}$ \\
\hline
\end{tabular}




\begin{tabular}{|c|c|c|c|}
\hline & $\begin{array}{l}\text { burnout em } \\
\text { enfermeiros. }\end{array}$ & 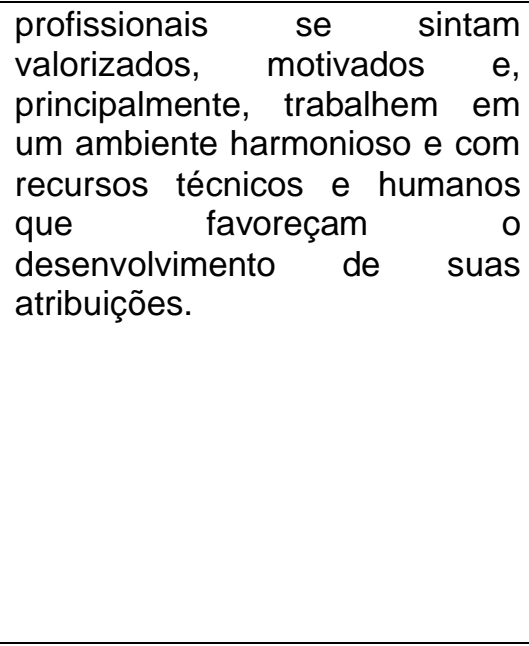 & 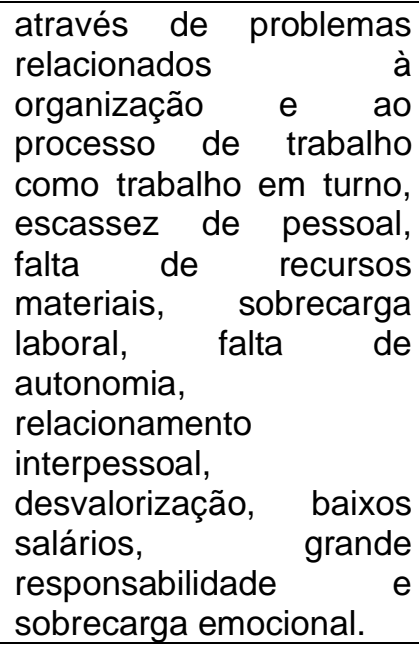 \\
\hline $\begin{array}{l}\text { VASCONCELOS } \\
, 2017 .\end{array}$ & $\begin{array}{l}\text { Burnout } \\
\text { sintomas } \\
\text { depressivos } \\
\text { enfermeiros de } \\
\text { terapia } \\
\text { intensiva: } \\
\text { análise de } \\
\text { relacionamento. }\end{array}$ & $\begin{array}{l}\text { As taxas de prevalência da } \\
\text { síndrome de burnout e da } \\
\text { sintomatologia depressiva são } \\
\text { alarmantes. Por meio da } \\
\text { experiência profissional dos } \\
\text { autores, observa-se que a } \\
\text { Política Nacional de Saúde do } \\
\text { Trabalhador encontra-se } \\
\text { distante de suprir as } \\
\text { necessidades desses } \\
\text { profissionais. É fundamental que } \\
\text { sejam adotadas estratégias de } \\
\text { enfretamento contra o burnout e } \\
\text { a sintomatologia depressiva no } \\
\text { âmbito ocupacional, uma vez } \\
\text { que isso pode refletir em } \\
\text { prejuízos na qualidade da } \\
\text { assistência prestada, assim } \\
\text { como na taxa de absenteísmo. }\end{array}$ & $\begin{array}{l}\text { Existiu uma correlação } \\
\text { em que, quanto maior foi } \\
\text { o nível de exaustão } \\
\text { emocional e de } \\
\text { despersonalização, maior } \\
\text { foi a sintomatologia } \\
\text { depressiva; e quanto } \\
\text { menor a realização } \\
\text { profissional } \\
\text { (inversamente } \\
\text { proporcional), maior a } \\
\text { sintomatologia } \\
\text { depressiva. }\end{array}$ \\
\hline $\begin{array}{l}\text { VASCONCELOS } \\
, 2018 .\end{array}$ & $\begin{array}{ll}\text { Preditores } & \text { da } \\
\text { síndrome } & \text { de } \\
\text { burnout } & \text { em } \\
\text { enfermeiros } & \text { de } \\
\text { unidade } & \text { de } \\
\text { terapia } & \\
\text { intensiva. } & \end{array}$ & $\begin{array}{l}\text { O estudo buscou investigar a } \\
\text { prevalência e possíveis fatores } \\
\text { sociodemográficos, hábitos de } \\
\text { vida e relacionados ao trabalho } \\
\text { que estão associados à } \\
\text { ocorrência da síndrome de } \\
\text { burnout. Os resultados } \\
\text { mostraram que a prevalência de } \\
\text { enfermeiros com a síndrome de } \\
\text { burnout correspondeu a } 14,3 \% \text {, } \\
\text { índice similar ao encontrado na } \\
\text { literatura. }\end{array}$ & $\begin{array}{l}\text { O estudo contribui com o } \\
\text { conhecimento na área de } \\
\text { saúde mental do } \\
\text { trabalhador, uma vez que } \\
\text { esta é a primeira } \\
\text { pesquisa nacional com } \\
\text { enfermeiros assistenciais } \\
\text { de unidade de terapia } \\
\text { intensiva que evidenciou } \\
\text { associação significativa } \\
\text { entre a duração das férias } \\
\text { e a ocorrência do burnout. }\end{array}$ \\
\hline
\end{tabular}

Fonte: a autora

Realizada leitura analítica dos artigos selecionados que possibilitou a organização dos assuntos por ordem de importância e a sintetização destas que visou à fixação das ideias essenciais para a solução do problema da pesquisa. Para operacionalizar a pesquisa os achados serão discutidos a seguir.

O ritmo apressado das transformações sociais, organizacionais e jurídicas tem influenciado no processo de saúde/ adoecimento do trabalhador. A exposição 
prolongada a estressores ambientais e situacionais resulta no estresse ocupacional, que por sua vez colabora com o aumento da exaustão emocional e da despersonalização, assim como com a baixa realização profissional (VASCONCELOS, 2017).

Verifica - se que esse trabalhador perde o sentido de sua relação com o trabalho; as atividades laborais deixam de ser significativas; e qualquer esforço the parece inútil, indicando um esgotamento, que advém após a utilização de toda a energia disponível. Nessa perspectiva, verifica-se que a síndrome de Burnout decorre de uma cronificação do estresse ocupacional, o qual tem consequências negativas relacionadas às esferas individuais, profissional, familiar, social e institucional, perdendo o trabalhador a capacidade de se (re)adaptar às demandas existentes no contexto laboral (TAVARES, 2014).

A Síndrome de Burnout é promulgada no estágio mais avançado do estresse. Tem seu início com o desânimo e a desmotivação com o trabalho, e pode chegar a doenças psicossomáticas, fazendo com que o profissional tenha elevadas taxas de absenteísmo, abdução temporário das funções, chegando até a aposentadoria por invalidez (OLIVEIRA, 2013).

Ao se tratar de estresse ocupacional, pesquisas apontam que os profissionais que exercem funções cuja profissão exige contatos interpessoais muito intensos, como em profissões de ajuda e/ou assistenciais, tais como médicos, enfermeiros, bombeiros, e outros, são os mais aptos a adquirir a síndrome de burnout. É notável o impacto multiplicador que o alto nível de estresse pode causar não só para o indivíduo em si, mas também para os recebedores de seus serviços (BEZERRA, 2009).

Entre as profissões que mais têm desenvolvido a síndrome do Burnout destacase a Enfermagem. Esse episódio relaciona-se ao intenso trabalho em turnos, à carência de reconhecimento profissional, às relações de trabalho e ao lidar constantemente com a sensação de impotência frente à morte. O Burnout afeta enfermeiros em todo o mundo e, em vários contextos de trabalho, fazendo com que desenvolvam sentimentos negativos em relação às necessidades dos pacientes, como frustração, frieza e indiferença (OLIVEIRA, 2013).

Essa condição acontece também porque as atribuições do enfermeiro demandam muita atenção, discernimento e responsabilidade, fatores que podem influenciar diretamente na saúde física e mental do trabalhador e condicionar ao surgimento do estresse ocupacional (VALERETTO, 2013). 
Para os profissionais que trabalham nas unidades de terapia intensiva (UTI) esta condição se agrava, pois estão mais expostas as condições dolorosas como a morte e o contato consecutivo com pacientes em estado grave ou terminal. Além disso, nestas unidades a equipe de enfermagem é quem se apresenta mais próximo do paciente. $O$ trabalho concretizado nestas unidades faz com que a equipe de enfermagem se torne um grupo de alto risco para desenvolver a Síndrome de Burnout (FONSECA, 2016).

A diminuição da incidência de burnout pode ocorrer através da habilidade para administrar as situações estressoras do cotidiano, para isso, o profissional pode fazer uso de estratégias, que pode ser deliberada como uma resposta comportamental que o indivíduo emite para se adaptar de melhor forma diante do evento estressor (GALINDO et al., 2012).

É necessário que o profissional desenvolva estratégias de enfrentamento visando diminuir a sobrecarga de trabalho, o desgaste emocional e físico, a insatisfação pessoal, e promover assim, uma melhor qualidade de vida, dentro e fora do ambiente terapêutico (MORENO et al., 2011).

As organizações estão cada vez mais preocupadas com a qualidade de vida, o bem-estar e a saúde física e mental de seus colaboradores, devido ao fato de que o burnout causa sérias repercussões, tanto no âmbito laboral como pessoal, além de refletir na qualidade da assistência prestada (VALERETTO, 2013).

No âmbito laboral, a instituição pode fornecer melhores condições de trabalho, tempo adequado para descanso, sistema de apoio ao trabalhador, condições físicas agradáveis e plano de carreira. Quando a instituição se preocupa apenas com o aspecto econômico, não se importando com as condições de trabalho de seus funcionários, há uma queda na produtividade e qualidade da assistência, portanto, as instituições podem e devem investir na qualidade de vida no trabalho de seus funcionários, vendo que esse investimento irá refletir também no modo em como a instituição é vista pelos seus clientes (MORENO et al., 2011). 


\section{CONSIDERAÇÕES FINAIS}

Diante do que foi exposto, fica evidente que o enfermeiro, pela função que exerce, necessita de uma atenção maior por parte da instituição de trabalho. As situações vivenciadas em seu dia a dia podem desencadear a Síndrome de Burnout.

O ambiente laboral interfere diretamente na saúde do profissional de enfermagem, sendo assim, cabe a instituição oferecer condições favoráveis de trabalho, com recursos humanos que sejam suficientes para atender a demanda, diminuindo tanto o desgaste físico quanto mental.

A criação de estratégias que promovam a saúde mental do trabalhador e previna agravos à saúde é uma importante ferramenta para que o enfermeiro possa realizar suas tarefas de maneira agradável e satisfatória, melhorando assim, a qualidade da assistência prestada.

O trabalho não deve ser um fardo pesado, mas uma atividade que proporcione satisfação e realização pessoal, portanto para se prevenir a Síndrome de Burnout devem-se adotar ações que valorize o profissional e the permita expressar a sua opinião sobre o ambiente de trabalho em que ele está inserido. 


\section{REFERÊNCIAS}

Barros, Dalton de Souza et al. Médicos plantonistas de unidade de terapia intensiva: perfil sócio-demográfico, condições de trabalho e fatores associados à síndrome de burnout. Revista Brasileira de Terapia Intensiva [online]. 2008, v. 20, n. 3 [Acessado 1 Julho 2021] , pp. 235-240. Disponível em: <https://doi.org/10.1590/S0103-507X2008000300005>. Epub 04 Nov 2008. ISSN 1982-4335. https://doi.org/10.1590/S0103-507X2008000300005.

FERREIRA, Ginúbia Braga. Síndrome de burnout na enfermagem hospitalar / intensivista: o que dizem os estudos? SANARE, Sobral - v. 16, n. 01, p. 100-108, 2017. Disponível em: file:///C:/Users/User/Downloads/1100-2656-1-SM.pdf. Acesso em 01 de Julho de 2021.

FONSECA, Thiago Carvalho de Paiva. Síndrome de burnout entre profissionais de enfermagem de unidades intensivas em um hospital público. Rev enferm UFPE on line., Recife, v. 10, n. 1, 296-303, 2016. Disponível em: file:///C:/Users/User/Downloads/10953-23880-1-PB.pdf. Acesso em 01 de Julho de 2021.

GALINDO, Renata Hirschle. Síndrome de burnout entre enfermeiros de um hospital geral da cidade de recife. Rev. esc. enferm. USP. v. 2, n. 46, p. 420-427, 2012. Disponível em: http://www.scielo.br/pdf/reeusp/v46n2/a21v46n2.pdf. Acesso em 01 de Julho de 2021.

MORESEI, E. Metodologia de pesquisa. Universidade Católica de Brasília, 2003.

MORENO, Fernanda Novaes. Estratégias e intervenções no enfrentamento da Síndrome de burnout. Revista de Enfermagem UERJ, v.1, n.19, p.140-145, 2011. Disponível em: https://pesquisa.bvsalud.org/portal/resource/pt/bde-20242. Acesso em 01 de Julho de 2021.

NOGUEIRA, Lilia de Souza. Burnout e ambiente de trabalho de enfermeiros em instituições públicas de saúde. Rev Bras Enferm [Internet], v. 71, n. 2, p. 358-365, 
2018. Disponível em: http://www.scielo.br/pdf/reben/v71n2/pt 0034-7167-reben-7102-0336.pdf. Acesso em 01 de Julho de 2021.

OLIVEIRA, Ramonyer Kayo Morais de. Síndrome de burnout em enfermeiros: uma revisão integrativa. R. pesq.: cuid. fundam. Online, v. 5, n. 1, p. 3168-3175, 2013. Disponível em: https://www.redalyc.org/pdf/5057/505750897035.pdf. Acesso em 01 de Julho de 2021.

ROSSI, Suelen Soares. A síndrome de burnout no enfermeiro: um estudo comparativo entre a atenção básica e setores fechados hospitalares. Rev. de pesquisa: cuidado é fundamental online, v. 2, n. edição especial, p. 381-384, 2010. Disponível em: http://www.seer.unirio.br/index.php/cuidadofundamental/article/view/950/pdf 159.

Acesso em 01 de Julho de 2021.

SILVA, Glébia Keila da Cunha. Síndrome de burnout em enfermeiros atuantes em unidade de terapia intensiva. Enferm. Foco, v. 5, n. 3-4, p. 75-78, 2014. Disponível em: http://revista.cofen.gov.br/index.php/enfermagem/article/view/563/245. Acesso em 01 de Julho de 2021.

SILVA, Arelly Barbosa do Nascimento. Síndrome de burnout em profissionais de enfermagem na unidade de terapia intensiva. Rev. Ciênc. Saúde Nova Esperança v. 14, n. 1 , p. $79-86,2016$. Disponível em: http://www.facene.com.br/wpcontent/uploads/2010/11/9.-S\%C3\%8DNDROME-DE-

BURNOUT 09.12.15 PRONTO.pdf. Acesso em 01 de Julho de 2021.

TAVARES, Kelly Fernanda Assis. Ocorrência da síndrome de Burnout em enfermeiros residentes. Acta Paul Enferm., v. 27, n. 3, p. 260-265, 2014. Disponível em: https://www.redalyc.org/pdf/3070/307031542012.pdf. Acesso em 01 de Julho de 2021.

VALERETTO, Fernanda Aparecida. Fatores desencadeantes do estresse ocupacional e da síndrome de burnout em enfermeiros. Revista Saúde Física \& Mental UNIABEU, v.3 n. 2, p. 1-11, 2013. Disponível em: https://revista.uniabeu.edu.br/index.php/SFM/article/view/1192/1038. Acesso em 01 de Julho de 2021. 
VASCONCELOS, Eduardo Motta de. Burnout e sintomas depressivos em enfermeiros de terapia intensiva: análise de relacionamento. Rev. Bras. Enferm., Brasília , v. 71, n. 1, p. 135-141, 2018. Disponível em: http://www.scielo.br/scielo.php?pid=S0034-

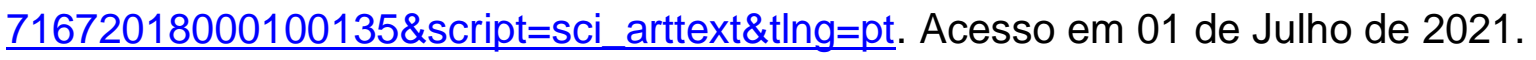

VASCONCELOS, Eduardo Motta de. Preditores da síndrome de burnout em enfermeiros de unidade de terapia intensiva. Rev. Gaúcha Enferm., v. 38, n. 4, p. 18, 2017. Disponível em: http://www.scielo.br/pdf/rgenf/v38n4/1983-1447-rgenf-38-04e65354.pdf. Acesso em 01 de Julho de 2021. 